\title{
LEADERSHIP SELECTION IN AN UNLIMITED THREE-ECHELON SUPPLY CHAIN
}

\author{
Peng Jia ${ }^{1}$, Hannan Amoozad Mahdiraji ${ }^{2}$, Kannan Govindan ${ }^{3}$, Ieva Meidute் \\ ${ }^{1}$ Transportation Management College, Dalian Maritime University, 1 Linghai Road, \\ Dalian, 116026, China \\ ${ }^{2}$ Management Department, University of Tehran, Tehran, Iran \\ ${ }^{3}$ Department of Business and Economics, University of Southern Denmark, Odense, Denmark \\ ${ }^{4}$ Business Management Faculty, Vilnius Gediminas Technical University, Vilnius, Lithuania \\ E-mails. ${ }^{2}$ h.amoozad@ut.ac.ir (corresponding author)
}

Received 09 October 2012; accepted 19 December 2012

\begin{abstract}
Supply chain (SC) management aims to increase the overall profit through improvement of various activities and components. Many contradictions between parts and different levels of a SC have been identified in order to achieve overall objectives. Such shortfalls may result in decreased strength and competitiveness of the SC. This paper considers the main conflicts related to inventory, pricing and marketing costs in an unlimited three-echelon supply chain. Aimed at avoiding a profit decrease, the research focuses on finding an equilibrium between inventory, pricing and marketing cost of an unlimited three-echelon SC. On each level, the best leadership option with the greatest payoff is sought for between $\mathrm{K}$ retailer, $\mathrm{M}$ manufacturer and $\mathrm{S}$ supplier. According to Stackelberg non-cooperative game theory, each SC level can become a decision-making leader depending on the available negotiating power. Consequently, three leadership types are modelled on each level and the total SC profit is calculated and compared to ascertain the best option. The authors of the article found that transfer of leadership from a retailer to supplier results in reduction of the total profit. In addition, the research focused on the main effects of parameters used in leadership models. Finally, validation of the proposed model was examined by simulation and Arena software, which indicated that models based on a game theory were performed accurately.
\end{abstract}

Keywords: supply chain, non-cooperative game, Stackelberg game, design of experiment, simulation models.

Reference to this paper should be made as follows: Jia, P.; Amoozad Mahdiraji, H.; Govindan, K.; Meidute, I. 2013. Leadership selection in an unlimited three-echelon supply chain, Journal of Business Economics and Management 14(3): 616-637.

JEL Classification: C44, C61, C63, C68, C72, C90, M11, L11.

\section{Introduction}

A management construct cannot be effectively used by practitioners and researchers if no uniform definition exists. Such is the case with the term "supply chain management", which has numerous definitions and little consensus on what it means (Mentzer et al. 2001). Supply chain paradigms of today have predominated over the field of 
business (Mentzer 2001). During the late 1950s, Forrester and his colleagues at the Massachusetts Institute of Technology developed a number of underlying ideas and theories (Blanchard 2010). The Council of Supply Chain Management Professionals (CSCMP) defines supply chain management (SCM) as the planning and management of all activities involved in sourcing and procurement, conversion and all logistics management activities (Stank et al. 2005). Many researchers believe that in the last decades, competition between companies has turn into competition between their supply chains (Jespersen, Larsen 2005).

Considering the role and importance of SCM, this concept is faced with many challenges and problems. Although no comprehensive model of SC issues exists, a literature review indicates that researchers are mostly interested in relevant information systems, marketing, financial management, logistical and organisational matters (Wang et al. 2007).

SCM is mostly focused on improving operations and increasing profits; thus, conflicting goals and objectives of two or more SC levels may result in problems for all levels and impact on the total profit. Numerous conflicting objectives of different components and levels may results in decreased strength and competitiveness of the entire supply chain. This paper considers the main conflicts related to inventory, pricing and marketing costs in an unlimited three-echelon SC. The game theory considers goals of all levels and players, which makes it a suitable and reliable tool for solving conflicting situations. On each level, the best leadership option with the greatest payoff is sought for between $\mathrm{K}$ retailer, $\mathrm{M}$ manufacturer and $\mathrm{S}$ supplier. According to Stackelberg non-cooperative game theory, each SC level can become a decision-making leader depending on the available negotiating power. Consequently, three leadership types are modelled on each level and the total SC profit is calculated and compared to ascertain the best option. Different models of leadership based on non-cooperative Stackelberg game theory are proposed to find the best option considering unlimited SC with three levels and three decision variables, namely inventory, marketing cost and pricing. The research considers shortages and incremental behaviour of a manufacturer as well as undertakes sensitivity analysis by design of experiment and validation of proposed models by simulation, which are its key contributions.

The paper is structured as follows: first, literature review is offered on SC coordination using game theory; next, assumption, steps and methodology pertaining to developed models are presented; then, variables and parameters are described. Three different leadership methods and three mathematical model based on non-cooperative game theory are then presented considering three types of negotiating power. The best leadership option is found simulating numerical examples with the help of design of experiment (DOE).

\section{Literature review}

As per definition, supply chain consists of all parties directly or indirectly involved in fulfilling a customer need (Chopra, Meindel 2007). This process involves all activities 
required to turn raw materials into a final product that is delivered to a customer (Gumus, Guneri 2007). Such activities and functions include new product development, marketing efforts, various other operations, distribution, financial and also customer services. A typical supply chain involves a variety of stages such as customers, retailers, wholesalers, distributors, manufacturers and raw material suppliers (Chopra, Meindel 2007).

The main game theory concept was devised by mathematical researchers from Argentina and Japan in 1940s. It was first used to prove theories with the help of mathematics and calculus. Later, it was applied in economics, industry and other practical sciences (Rasmusen, Blackwell 2005). In 1950, John Nash presented equilibrium for cooperative situations (Nash 1950a). He also developed a model for bargaining problems (Nash 1950b); and a year later, he presented an equilibrium point for non-cooperative situations (Nash 1951). This research is primarily concerned with the use of game theory in general and non-cooperative Stackelberg games in particular in supply chain management. Review of similar researches suggests that:

1. Some scientists have focused on the use of Nash equilibrium point in supply chain coordination by the use of profit sharing contract (Feng et al. 2007; Jiazhen, Qin 2008; Feng 2008; Ying et al. 2007; Jaber et al. 2006; Bai, Wang 2008; Xu, Zhong 2011; Liu, Zhang 2006; Wang et al. 2009).

2. Others used Nash and Stackelberg games and compared their results in supply chain coordination and cooperation problems (Leng, Parlar 2010; Arda, Hennet 2005).

3. Many focused on the use of other kinds of coordinating contracts such as buyback, rebate, cost sharing, profit sharing discount models, option contracts and benefit sharing in multi-echelon SC problems (Cachon, Lariviere 2005; Yali, Zhanguo 2010; Chen, Zhang 2008; Cao et al. 2007; Cachon, Lariviere 1999; Zhang, Huang 2010; Cachon, Lariviere 2001; Leng, Parlar 2009; Xiao, Qi 2008; Chen, Xiao 2009; Xiao et al. 2007; Stein, Ginevicius 2010a; Stein 2010).

4. Some used Shapley value equilibrium and Eliasberg model for coordination and cooperation problems in SC (Bahinipati et al. 2009; Zhao et al. 2010; Leng, Zhu 2009).

5. Finally, some papers focus on other optimisation tools such as queuing theory, Markov chain, backward induction, stochastic programming and genetic algorithm for solving coordination and cooperation problems in a supply chain, mostly in incomplete information games situations (Cachon, Kok 2010; Hennet, Arda 2008; Stein, Ginevicius 2010b; Zhen et al. 2006; Kaviani et al. 2011; Gupta, Weerawat 2006).

\section{Research methodology and assumptions}

Main steps used for the selection of leadership in an unlimited three-echelon supply chain are presented in Figure 1. 


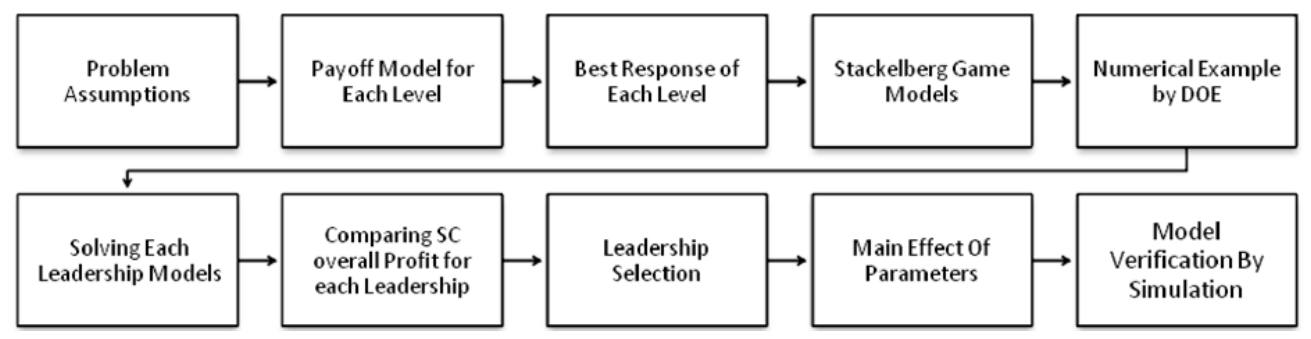

Fig. 1. Research methodology

\subsection{Assumptions}

1. Supply chain consists of $\mathrm{K}$ retailer, $\mathrm{M}$ manufacturer and $\mathrm{S}$ supplier (Jaafarnejad et al. 2012)

$$
\left\{\begin{array}{l}
s_{1} \\
s_{2} \\
\cdot \\
\cdot \\
\cdot \\
s_{M}
\end{array}\right\} \Leftrightarrow\left\{\begin{array}{l}
n_{1} \\
n_{2} \\
\cdot \\
\cdot \\
\cdot \\
n_{N}
\end{array}\right\} \Leftrightarrow\left\{\begin{array}{l}
r_{1} \\
r_{2} \\
\cdot \\
\cdot \\
\cdot \\
r_{K}
\end{array}\right\} \leftrightarrow \text { Customer. }
$$

2. The product demand function depends on a price and marketing costs. This function is non-linear $D_{n}=k \cdot P_{r_{n}}{ }^{-\alpha} \cdot C_{M_{n}}{ }^{\beta}$, thus standard deterministic inventory models are used. Alpha considers negative price behaviour in the model devised by the article authors (Abad 1994; Lee 1993; Lee et al. 1996; Kim, Lee 1998; Jung, Cerry 2001; Jung, Cerry 2005; Esmaeili 2008; Jaafarnejad et al. 2012).

3 . In case of a manufacturer, shortages and stockout are allowed; consequently, shortage costs are considered during the stockout period. The total relative cost for the manufacturer when producing incrementally, are calculated as provided below (Oganezov 2006; Wang, Tang 2009; Chakrabortty et al. 2010; Chang 2008; Pentico et al. 2009; Jaafarnejad et al. 2012):

$$
\left[C_{h_{n}} \times \frac{\left(\lambda_{n} \cdot Q_{r_{n}}-B_{n}\right)^{2}}{2 \cdot \lambda_{n} \cdot Q_{r_{n}}}\right]+\left[\frac{C_{B_{n}} \cdot B_{n}^{2}}{2 \cdot \lambda_{n} \cdot Q_{r_{n}}}\right] .
$$

In terms of this research, pricing, inventory and marketing costs are the decision variables.

4. Production unit cost is a nonlinear function $C_{P_{n}}=u \cdot D_{n}^{-\gamma}$ which is related to the demand and decreases with growing demand (Bazaraa et al. 1993).

5. Each manufacturer sells a specific product to a specific retailer. However, suppliers sell their raw materials to any manufacturer as needed.

6. Irrespective of the level of the supply chain, to which it belongs, each player has a reasonable behaviour and opts for higher profit and lower cost.

7. As every player can act as a leader based on dominance and negotiating power, three types of leadership are considered. 


\subsection{Notations}

Table 1 provides variables and parameters used for models that are designed in following section.

Table 1. Variable and parameters

\begin{tabular}{lclc}
\hline Description & Note & Description & Note \\
\hline Ordering cost from s to $n$ & $C_{O_{s n}}$ & Retailer's margin & $G_{r}$ \\
\hline Production function parameters & $u, \gamma$ & Selling price from r to a customer & $P_{r_{n}}$ \\
\hline Manufacturer holding cost & $C_{h_{n}}$ & Selling price from n to r & $P_{n}$ \\
\hline Manufacturer stockout & $B_{n}$ & Product demand & $D_{n}$ \\
\hline Manufacturer's stockout cost & $C_{B_{n}}$ & Marketing cost for product n & $C_{M_{n}}$ \\
\hline Manufacturer's margin & $G_{n}$ & Price and marketing and demand coefficient & $k$, a, $\beta$ \\
\hline Manufacturer's total revenue & $T R_{n}$ & Retailer's setup cost & $C_{s_{r n}}$ \\
\hline Manufacturer's total cost & $T C_{n}$ & Manufacturer's production quantity & $Q_{r_{n}}$ \\
\hline $\begin{array}{l}\text { Manufacturer's production capacity } \\
\text { Supplier's margin }\end{array}$ & $P C_{n}$ & Holding Cost coefficient for a retailer & $k_{n}^{\prime}$ \\
\hline Supplier's total revenue & $G_{S}$ & Retailer's total revenue & $T R_{r}$ \\
\hline Supplier's total cost & $T R_{S}$ & Retailer's total cost & $T C_{r}$ \\
\hline $\begin{array}{l}\text { Supplier's unit cost for each unit of } \\
\text { raw materials }\end{array}$ & $G_{S}$ & Retailer's total payoff & Raw material coefficient in product $n$ \\
\hline $\begin{array}{l}\text { Holding coefficient cost for a } \\
\text { supplier }\end{array}$ & $G_{S}$ & & $Z_{r}$ \\
\hline Supplier's ordering cost & $k_{S_{s}}$ & Raw material price from s to $n$ & $k_{S_{n}}$ \\
\hline
\end{tabular}

\section{Modelling process}

Based on the research methodology and using assumptions and notations described in previous sections of the article, the primary model for each player is identified. A retailer ( $r$ ) confronts holding and setup costs as well purchasing cost from manufacturer. In addition, to participate in a supply chain, a retailer should have a positive sales margin. Finally a retailer's income involves the revenue achieved by selling goods to the final customer. Considering the above, retailer's payoff function and its constraints are presented in (2) (Jaafarnejad et al. 2012).

$$
\begin{gathered}
\operatorname{Max} Z_{r}=\left(k \cdot P_{r_{n}}^{-\alpha} \cdot C_{M_{n}}^{\beta}\left[P_{r_{n}}-P_{n}-C_{M_{n}}-C_{S_{r n}} \cdot Q_{r_{n}}^{-1}\right]\right)-\frac{1}{2} \times Q_{r_{n}} \times k_{n}^{\prime} \times P_{n}, \\
\text { s.t: }
\end{gathered}
$$




$$
\begin{gathered}
P_{r_{n}}-P_{n} \geq 0, \\
D_{n}=k \cdot P_{r_{n}}{ }^{-\alpha} \cdot C_{M_{n}}{ }^{\beta} \geq 0, \\
D_{n} \leq P C_{n}, \\
k>0, \alpha>1,0<\beta<1, \alpha-\beta>1 .
\end{gathered}
$$

Manufacturer's $(n)$ confront holding, setup, ordering and stockout as well as purchasing and production costs. On the other hand, a manufacturer receives revenues from selling the final product to a retailer in large amounts. The production is incremental; in addition, unit production costs are related to products sold to a retailer. In 2012, Jaafarnejad et al. proposed a manufacturer's model, which does not include unit production costs while computing gross revenues in an objective function; consequently, the model became unbounded in many situations. Consequently, the authors of the article considered this problem and revised the manufacturer's model. It was noticed that manufacturer and retailer leadership model has to be revised due accordingly. Considering the aforementioned, manufacturer's payoff function and its constraints are shown in (3).

$$
\begin{gathered}
\operatorname{Max} Z_{n}=\left[\left(P_{n}-\sum_{s=1}^{M}\left(k_{s_{n}} \cdot C_{p_{s}}\right)-u \cdot D_{n}^{-\gamma}\right) \times D_{n}\right]-\left[\left(\sum_{s=1}^{m}\left(C_{O_{s n}}\right)+C_{S_{n}}\right) \times\right. \\
\left.\frac{D_{n}}{Q_{r_{n}}}\right]-\left[C_{h_{n}} \times \frac{\left(\lambda_{n} \cdot Q_{r_{n}}-B_{n}\right)^{2}}{2 \cdot \lambda_{n} \cdot Q_{r_{n}}}\right]-\left[\frac{C_{B_{n}} \cdot B_{n}^{2}}{2 \cdot \lambda_{n} \cdot Q_{r_{n}}}\right] \\
\text { s.t: } \\
P_{n}-\left[\sum_{s=1}^{m}\left(C_{P_{s}} \cdot k_{s_{n}}\right)+u \cdot D_{n}^{-\gamma}\right] \geq 0, \\
C P_{n} \geq D_{n}, \\
D_{n}=k \cdot P_{r_{n}}^{-\alpha} \cdot C_{M_{n}}^{\beta}, \\
k>0, u>0, \alpha>1,0<\beta<1,0<\gamma<1, \alpha-\beta>1 .
\end{gathered}
$$

Suppliers confront costs related to holding, setup, ordering as well as purchasing or acquiring raw materials. In contrast, every supplier gains revenues by selling raw materials to manufacturers depending on their usage for production. Considering the aforementioned, a supplier's payoff function and constraints are depicted in (4) (Jaafarnejad et al. 2012).

$$
\begin{gathered}
\operatorname{Max} Z_{S}=\left[\left(C_{P_{S}}-C_{S_{o}}\right) \times \sum_{n=1}^{N} k_{S_{n}} \cdot D_{n}\right]-\left[\sum_{n=1}^{N} \frac{D_{n}}{Q_{r_{n}}} \times C_{S_{s}}\right]-\left[\sum_{n=1}^{N} k_{S_{s}} \cdot C_{S_{o}} \cdot k_{S_{n}} \cdot \frac{Q_{r_{n}}}{2}\right], \\
\text { s.t: } \\
C_{P_{S}}-C_{S_{o}} \geq 0 \\
D_{n}=k \cdot P_{r_{n}}^{-\alpha} \cdot C_{M_{n}}^{\beta}, \\
k>0, u>0, \alpha>1,0<\beta<1,0<\gamma<1, \alpha-\beta>1 .
\end{gathered}
$$




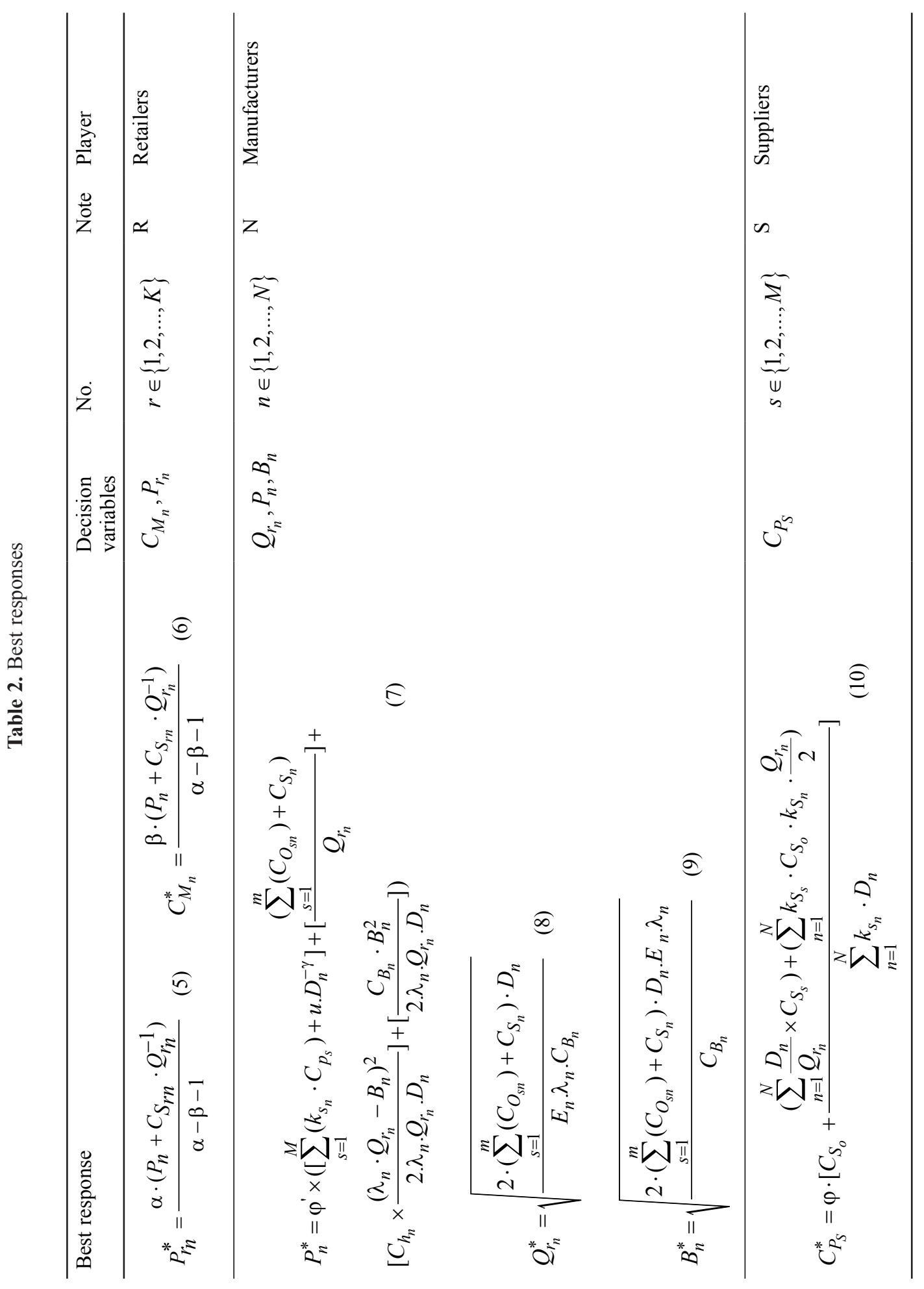


Each player of a three-level supply chain acts in its best interest when playing a game. Considering reasonable behaviour of each player as well as Nash best response principle, the best decision for each player of a three-echelon SC is identified by derivation of the payoff function to decision variables. The first order condition of each payoff function is used for the best response and the second condition is used for concavity analysis. By calculating the determinant of Hessian matrix for each player depending on its decision variables, it can be concluded that all models are concave to their decision variables; thus, optimal solution for the proposed models are definable. Table 2 represents the best response for each player if Nash principle is used, by calculating the first order condition of each player's payoff function according to their decision variables.

Once modelling is completed and the best response for each player is found, it is time to finalise the research and produce the leadership model for coordination of a three-level supply chain by Stackelberg non-cooperative approach. As three levels are included in the SC game, three types of leadership are possible. Each level - a supplier, manufacturer and retailer - can act as a leader while the remaining two would play the role of a follower. In this research, based on a make of a system and type of a supply chain, three leadership followership systems were considered. The main objective is to maximise the total profit based on the best response of followers. Consequently, the sum of leader payoffs will be the objective function and the best response of followers will act as constraints. The aforementioned basic constraints are considered in other models as well. Figure 2 presents leadership types considered in this research.

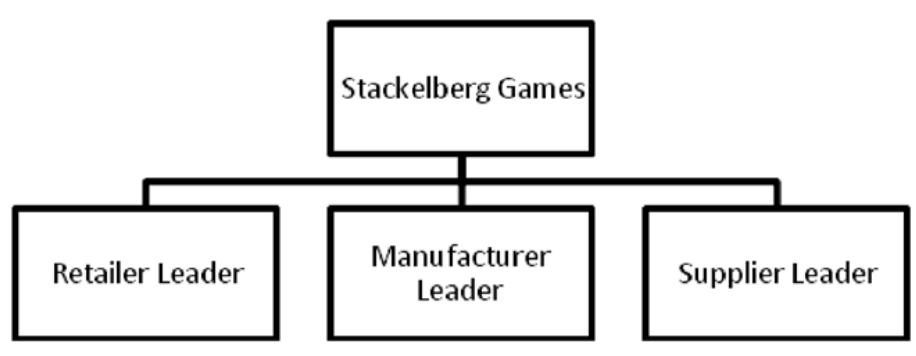

Fig. 2. Leadership types

\subsection{Retailer leadership according to stackelberg model}

The first model describes the situation with retailers as leaders and manufacturers and suppliers as followers. The objective function insist on maximising the retailer's profit, first four constraints explain the rational behaviour of followers and the remaining constraint describes the logic of the game, namely: demand should exist and the selling price established by each player for the next level should be greater than the purchasing price from previous level. Other relevant information is presented in Table 3. 
Table 3. Retailer leadership situation

$$
\begin{aligned}
& \begin{array}{llll}
\hline \text { Inputs } & \text { Condition/Model } & \text { Outputs } & \text { Figure } \\
\hline K_{s_{n}}, C_{O_{s n}}, C_{S_{n}}, C_{s_{r_{n}}}, C_{S_{s}}, C P_{n} & \text { Leader: Retailer } & & \\
k, \alpha, \beta, \gamma, M, N, K, C_{B_{n}} & \text { Follower: } & C_{M}^{*}, P_{r_{n}}^{*} & \\
C_{h_{n}}, K_{s_{s}}, \varphi_{s}, \varphi_{n}^{\prime}, k_{n}^{\prime}, u & \text { Sanufacturer \& } & & \\
& T Z_{r}=\sum_{r=1}^{K} Z_{r} & \\
& S . T: C_{P_{s}}^{*}, Q_{r_{n}}^{*}, B_{n}^{*}, P_{n}^{*} & \\
& & \\
\end{array} \\
& \operatorname{MaxTZ}_{r}=\sum_{r=1}^{K}\left[\left(k \cdot P_{r_{n}}^{-\alpha} \cdot C_{M_{n}}^{\beta}\left[P_{r_{n}}-P_{n}-C_{M_{n}}-C_{S_{m}} \cdot Q_{r_{n}}^{-1}\right]\right)-\frac{1}{2} \times Q_{r_{n}} \times k_{n}^{\prime} \times P_{n}\right] \\
& \operatorname{MaxTZ}_{r}=\sum_{r=1}^{K}\left[\left(k \cdot P_{r_{n}}^{-\alpha} \cdot C_{M_{n}}^{\beta}\left[P_{r_{n}}-P_{n}-C_{M_{n}}-C_{S_{m}} \cdot Q_{r_{n}}^{-1}\right]\right)-\frac{1}{2} \times Q_{r_{n}} \times k_{n}^{\prime} \times P_{n}\right] \\
& P_{n}=\varphi_{n}^{\prime} \times\left(\begin{array}{l}
{\left[\sum_{s=1}^{M}\left(k_{s_{n}} \cdot C_{p_{s}}\right)+u \cdot D_{n}^{-\gamma}\right]+\left[\frac{\left(\sum_{s=1}^{m}\left(C_{O_{s n}}\right)+C_{S_{n}}\right)}{Q_{r_{n}}}\right]+} \\
{\left[C_{h_{n}} \times \frac{\left(\lambda_{n} \cdot Q_{r_{n}}-B_{n}\right)^{2}}{2 \cdot \lambda_{n} \cdot Q_{r_{n}} \cdot D_{n}}\right]+\left[\frac{C_{B_{n}} \cdot B_{n}^{2}}{2 \cdot \lambda_{n} Q_{r_{n}} \cdot D_{n}}\right]}
\end{array}\right) ; \quad \forall n \in N \\
& Q_{r_{n}}=\sqrt{\frac{2 \cdot\left(\sum_{s=1}^{m}\left(C_{O_{s n}}\right)+C_{S_{n}}\right) \cdot D_{n}}{E_{n} \cdot \lambda_{n} \cdot C_{B_{n}}}} ; \quad \forall n \in N \\
& B_{n}=\sqrt{\frac{2 \cdot\left(\sum_{s=1}^{m}\left(C_{O_{s n}}\right)+C_{S_{n}}\right) \cdot D_{n} \cdot \lambda_{n} \cdot E_{n}}{C_{B_{n}}}} ; \forall n \in N \\
& C_{P_{S}}=\varphi_{s} \cdot\left[C_{S_{o}}+\frac{\left(\sum_{n=1}^{N} \frac{D_{n}}{Q_{r_{n}}} \times C_{S_{s}}\right)+\left(\sum_{n=1}^{N} k_{S_{s}} \cdot C_{S_{o}} \cdot k_{S_{n}} \cdot \frac{Q_{r_{n}}}{2}\right)}{\sum_{n=1}^{N} k_{s_{n}} \cdot D_{n}}\right] ; \forall s \in M \\
& D_{n}=k \cdot P_{r_{n}}^{-\alpha} \cdot C_{M_{n}}^{\beta} ; \forall n \in N
\end{aligned}
$$




$$
\begin{aligned}
& P_{n}-\left[\sum_{s=1}^{m}\left(C_{P_{s}} \cdot k_{s_{n}}\right)+u \cdot D_{n}^{-\gamma}\right] \geq 0 \\
& P_{r_{n}}-P_{n} \geq 0 ; \forall r \in K, \forall n \in N \\
& D_{n} \geq 0 ; \forall n \in N \\
& D_{n} \leq P C_{n} ; \forall n \in N \\
& \quad \lambda_{n}=1-\frac{D_{n}}{P C_{n}} ; \forall n \in N
\end{aligned}
$$

\subsection{Manufacturer leadership according to stackelberg model}

The first model describes the situation where manufacturers act as leaders while retailers and suppliers are followers. The objective function insists on maximising the manufacturer's profit, first three constraints explain the rational behaviour of followers and the remaining constraint describes the logic of the game, namely: demand should exist and the selling price established by each player for the next level should be greater than the purchasing price from previous level. Other relevant information is presented in Table 4.

Table 4. Manufacturer leadership situation

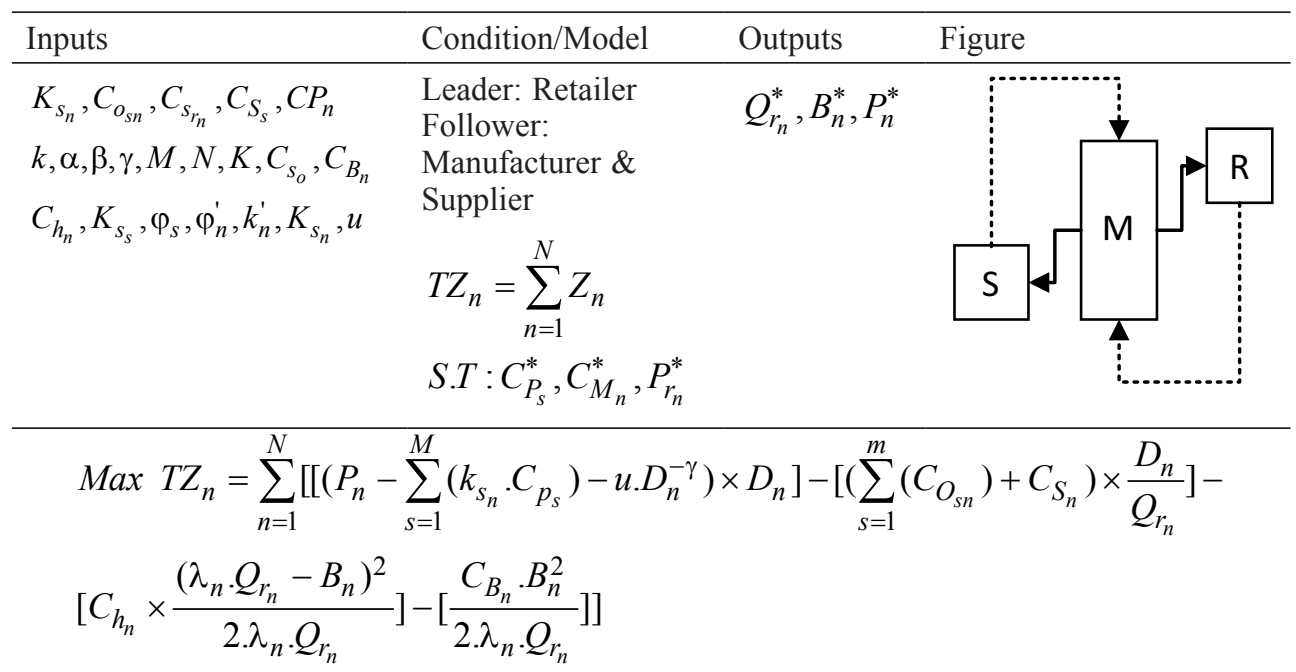

$$
\begin{gathered}
C_{M_{n}}=\frac{\beta \cdot\left(P_{n}+C_{S_{r n}} \cdot Q_{r_{n}}^{-1}\right)}{\alpha-\beta-1} ; \forall n \in N \\
P_{r_{n}}=\frac{\alpha \cdot\left(P_{n}+C_{S_{r n}} \cdot Q_{r_{n}}^{-1}\right)}{\alpha-\beta-1} ; \forall n \in N
\end{gathered}
$$




$$
\begin{gathered}
C_{P_{S}}=\varphi_{S} \cdot\left[C_{S_{o}}+\frac{\left(\sum_{n=1}^{N} \frac{D_{n}}{Q_{r_{n}}} \times C_{S_{s}}\right)+\left(\sum_{n=1}^{N} k_{S_{s}} \cdot C_{S_{o}} \cdot k_{S_{n}} \cdot \frac{Q_{r_{n}}}{2}\right)}{\sum_{n=1}^{N} k_{S_{n}} \cdot D_{n}} ; \forall s \in M\right. \\
P_{n}-\left[\sum_{s=1}^{m}\left(C_{P_{s}} \cdot k_{S_{n}}\right)+u \cdot D_{n}^{-\gamma}\right] \geq 0 ; \forall n \in N \\
P_{r_{n}}-P_{n} \geq 0 ; \forall n \in N \\
\lambda_{n}=1-\frac{D_{n}}{C P_{n}} ; \quad \forall n \in N \\
D_{n}=k \cdot P_{r_{n}}^{-\alpha} \cdot C_{M_{n}}^{\beta} ; \quad \forall n \in N \\
D_{n} \geq 0 ; \forall n \in N \\
C P_{n} \geq D_{n} ; \quad \forall n \in N
\end{gathered}
$$

\subsection{Supplier leadership according to stackelberg model}

The first model describes the situation where suppliers act as leaders while manufacturers and retailers are followers. The objective function insists on maximising the supplier's profit, first five constraints explain the rational behaviour of followers and the remaining constraint describe the logic of the game, namely: demand should exist and the selling price established by each player for the next level should be greater than the purchasing price from previous level. Other relevant information is presented in Table 5.

Table 5. Supplier leadership situation

\begin{tabular}{llll}
\hline Inputs & Condition/Model & Outputs & Figure \\
\hline$K_{s_{n}}, C_{o_{s n}}, C_{S_{n}}, C_{S_{s}}, C P_{n}$ & Leader: Retailer & Follower: Manufacturer & $C_{P_{s}}^{*}$ \\
$k, \alpha, \beta, \gamma, M, N, K, u$ & \& Supplier & \\
$C_{h_{n}}, K_{s_{s}}, \varphi_{n}^{\prime}, k_{s}^{\prime}, C_{B_{n}}, C_{s_{o}}$ & $T Z_{s}=\sum_{s=1}^{M} Z_{s}$ \\
& $S . T: Q_{r_{n}}^{*}, B_{n}^{*}, P_{n}^{*}, C_{M_{n}}^{*}, P_{r_{n}}^{*}$ & &
\end{tabular}

$\operatorname{Max} T Z_{S}=\sum_{s=1}^{M}\left[\left[\left(C_{P_{S}}-C_{S_{o}}\right) \times \sum_{n=1}^{N} k_{S_{n}} \cdot D_{n}\right]-\left[\sum_{n=1}^{N} \frac{D_{n}}{Q_{r_{n}}} \times C_{S_{S}}\right]-\left[\sum_{n=1}^{N} k_{S_{S}} \cdot C_{S_{o}} \cdot k_{S_{n}} \cdot \frac{Q_{r_{n}}}{2}\right]\right]$ s.t:

$$
P_{r_{n}}=\frac{\alpha \cdot\left(P_{n}+C_{S_{r n}} \cdot Q_{r_{n}}^{-1}\right)}{\alpha-\beta-1} ; \forall n \in N
$$




$$
\begin{aligned}
& C_{M_{n}}=\frac{\beta \cdot\left(P_{n}+C_{S_{r n}} \cdot Q_{r_{n}}^{-1}\right)}{\alpha-\beta-1} ; \forall n \in N \\
& Q_{r_{n}}=\sqrt{\frac{2 \cdot\left(\sum_{s=1}^{m}\left(C_{O_{s n}}\right)+C_{S_{n}}\right) \cdot D_{n}}{E_{n} \cdot \lambda_{n} \cdot C_{B_{n}}}} ; \quad \forall n \in N \\
& B_{n}=\sqrt{\frac{2 \cdot\left(\sum_{s=1}^{m}\left(C_{O_{s n}}\right)+C_{S_{n}}\right) \cdot D_{n} \cdot \lambda_{n} \cdot E_{n}}{C_{B_{n}}}} ; \forall n \in N \\
& \begin{array}{l}
P_{n}=\varphi_{n}{ }^{\prime} \times\left(\left[\sum_{s=1}^{M}\left(k_{s_{n}} \cdot C_{p_{s}}\right)+u \cdot D_{n}^{-\gamma}\right]+\left[\frac{\left(\sum_{s=1}^{m}\left(C_{O_{s n}}\right)+C_{S_{n}}\right)}{Q_{r_{n}}}\right]+\right. \\
\left.\left[C_{h_{n}} \times \frac{\left(\lambda_{n} \cdot Q_{r_{n}}-B_{n}\right)^{2}}{2 \cdot \lambda_{n} \cdot Q_{r_{n}} \cdot D_{n}}\right]+\left[\frac{C_{B_{n}} \cdot B_{n}^{2}}{2 \cdot \lambda_{n} \cdot Q_{r_{n}} \cdot D_{n}}\right]\right) ; \forall n \in N
\end{array} \\
& D_{n}=k \cdot P_{r_{n}}^{-\alpha} \cdot C_{M_{n}}^{\beta} ; \forall n \in N \\
& D_{n} \geq 0 ; \forall n \in N \\
& \lambda_{n}=1-\frac{D_{n}}{P C_{n}} ; \forall n \in N \\
& P_{r_{n}}-P_{n} \geq 0 ; \forall n \in N \\
& P_{n}-\left[\sum_{s=1}^{m}\left(C_{P_{s}} \cdot k_{s_{n}}\right)+u \cdot D_{n}^{-\gamma}\right] \geq 0 ; \forall n \in N
\end{aligned}
$$

\section{Numerical example}

Considering the models mentioned above, for sensitivity analysis and leadership selection, a three-echelon supply chain including 2 suppliers, 2 manufacturers and 2 retailers was designed. Table 6 indicates the numerical values of parameters in a proposed supply chain. 
Table 6. Initial data for the numerical example

\begin{tabular}{|c|c|c|c|}
\hline Amount & Par & Amount & Par \\
\hline 2 & M & 2 & $\mathrm{R}$ \\
\hline 4 & $C_{S_{r}}(1)$ & 2 & S \\
\hline 0.15 & $k_{1}^{\prime}$ & 5 & $C_{S_{r}}(2)$ \\
\hline 1.1 & $\varphi_{1}^{\prime}$ & 0.2 & $k_{2}^{\prime}$ \\
\hline 3 & $k_{s n}(11)$ & 1.15 & $\varphi_{2}^{\prime}$ \\
\hline 3 & $k_{s n}(21)$ & 4 & $k_{s n}(12)$ \\
\hline 6 & $\mathrm{Co}_{s n}(11)$ & 3 & $k_{s n}(22)$ \\
\hline 4 & $\mathrm{Co}_{s n}(21)$ & 5 & $\mathrm{Co}_{s n}(12)$ \\
\hline 1 & $C_{B}(1)=C_{B}(2)$ & 6 & $\mathrm{Co}_{s n}(22)$ \\
\hline 25 & $C_{S_{S}}(1)$ & 0.5 & $C_{h_{n}}(1)=C_{h_{n}}(2)$ \\
\hline 0.15 & $k_{s_{S}}(1)$ & 24 & $C_{S_{S}}(2)$ \\
\hline 2 & $C_{S_{o}}(1)$ & 0.2 & $k_{s_{S}}(2)$ \\
\hline 15 & $P C(1)=P C(2)$ & 1.5 & $C_{S_{o}}(2)$ \\
\hline 8 & $C_{S_{n}}(2)$ & 7 & $C_{S_{n}}(1)$ \\
\hline 1.1 & $\varphi_{2}$ & 1.15 & $\varphi_{1}$ \\
\hline
\end{tabular}

To select the best type of leadership and analyse the sensitivity of the total profit, five constants were selected from demand and production nonlinear functions including $\alpha, \beta, \gamma, k, u$. The lower and upper bounds of these five elements are provided in Table 7 .

Table 7. Key parameters for sensitivity analysis

\begin{tabular}{lll}
\hline Max & Min & \\
\hline 1.25 & 1.2 & $\alpha$ \\
\hline 0.15 & 0.05 & $\beta$ \\
\hline 0.1 & 0.01 & $\gamma$ \\
\hline 4000 & 3000 & $k$ \\
\hline 4 & 2 & $u$ \\
\hline
\end{tabular}

Using design of experiment (DOE) and $2^{k-p}$ experiments as well as including one central point in each block, 17 different experiments were designed with the help of MINITAB 16.5 software. The experiments are presented in Table 8. 
Table 8. Types of experiments

\begin{tabular}{llllll}
\hline Design & $\gamma$ & $\mathbf{U}$ & $\mathbf{K}$ & $\alpha$ & $\beta$ \\
\hline 1 & 0.01 & 4 & 4000 & 1.2 & 0.15 \\
\hline 2 & 0.1 & 2 & 3000 & 1.2 & 0.05 \\
\hline 3 & 0.01 & 4 & 3000 & 1.2 & 0.05 \\
\hline 4 & 0.1 & 4 & 3000 & 1.25 & 0.05 \\
\hline 5 & 0.1 & 4 & 4000 & 1.25 & 0.15 \\
\hline 6 & 0.1 & 4 & 3000 & 1.2 & 0.15 \\
\hline 7 & 0.055 & 3 & 3500 & 1.225 & 0.1 \\
\hline 8 & 0.01 & 4 & 3000 & 1.25 & 0.15 \\
\hline 9 & 0.1 & 2 & 3000 & 1.25 & 0.15 \\
\hline 10 & 0.01 & 2 & 3000 & 1.2 & 0.15 \\
\hline 11 & 0.01 & 2 & 3000 & 1.25 & 0.05 \\
\hline 12 & 0.1 & 4 & 4000 & 1.2 & 0.05 \\
\hline 13 & 0.01 & 2 & 4000 & 1.2 & 0.05 \\
\hline 14 & 0.1 & 2 & 4000 & 1.2 & 0.15 \\
\hline 15 & 0.01 & 2 & 4000 & 1.25 & 0.15 \\
\hline 16 & 0.01 & 4 & 4000 & 1.25 & 0.05 \\
\hline 17 & 0.1 & 2 & 4000 & 1.25 & 0.05 \\
\hline
\end{tabular}

The experiments listed in Table 7 were used in all three leadership models. The models were coded, debugged and solved using LINGO 11. The total profit in case of each different type of leadership was calculated. The results are presented in Table 9.

Table 9. The total profit of the supply chain by type of leadership

\begin{tabular}{cccc}
\hline \multicolumn{5}{c}{ The total profit of the supply chain } \\
\hline Supplier leadership & Manufacturer leadership & Retailer leadership & Design \\
\hline 2631 & 2686 & 3432 & 1 \\
\hline 1328 & 1332 & 1838 & 2 \\
\hline 1293 & 1331 & 1800 & 3 \\
\hline 956 & 997 & 1370 & 4 \\
\hline 1820 & 1866 & 2507 & 5 \\
\hline 1866 & 1904 & 2554 & 6 \\
\hline 1548 & 1577 & 2129 & 7 \\
\hline 1314 & 1361 & 1852 & 8 \\
\hline 1307 & 1362 & 1878 & 9 \\
\hline 1888 & 1928 & 2568 & 10 \\
\hline 994 & 1025 & 1395 & 11 \\
\hline 1824 & 1854 & 2442 & 12 \\
\hline 1853 & 1901 & 2470 & 13 \\
\hline 2659 & 2686 & 3455 & 14 \\
\hline 1851 & 1925 & 2529 & 15 \\
\hline 1344 & 1399 & 1844 & 16 \\
\hline 1395 & 1443 & 1890 & 17 \\
\hline
\end{tabular}

Using the two paired test, results of all three types of leadership in a supply chain were compared. The results from MINITAB 16.5 software are provided below. The authors 
of the article concluded that retailer leadership ranked first and manufacturer and supplier leaderships ranked second and third, respectively. Consequently, it is proposed that if negotiating power increases by moving from the end of chain to the beginning, the total profit would decrease.

\begin{tabular}{|c|c|c|c|c|}
\hline \multicolumn{5}{|c|}{ Paired T-Test and Cl: ZSC(R); ZSC(N) } \\
\hline \multicolumn{5}{|c|}{ Paired $\mathrm{T}$ for $\mathrm{ZSC}(\mathrm{R})-\mathrm{ZSC}(\mathrm{N})$} \\
\hline & $\mathrm{N}$ & Mean & StDev & SE Mean \\
\hline ZSC(R) & 17 & 2233 & 599 & 145 \\
\hline $\mathrm{ZSC}(\mathrm{N})$ & 17 & 1681 & 487 & 118 \\
\hline Difference & 17 & 551.6 & 116.1 & 28.2 \\
\hline \multicolumn{5}{|c|}{ 95\% lower bound for mean difference: 502.5} \\
\hline \multicolumn{5}{|c|}{$\mathrm{T}$-Test of mean difference $=0(\mathrm{vs}>0): \mathrm{T}$-Value $=19.59 \mathrm{P}$-Value $=0.000$} \\
\hline \multicolumn{5}{|c|}{ Paired T-Test and Cl: ZSC(R); ZSC(S) } \\
\hline \multicolumn{5}{|c|}{ Paired $\mathrm{T}$ for $\mathrm{ZSC}(\mathrm{R})-\mathrm{ZSC}(\mathrm{S})$} \\
\hline & $\mathrm{N}$ & Mean & StDev & SE Mean \\
\hline $\mathrm{ZSC}(\mathrm{R})$ & 17 & 2233 & 599 & 145 \\
\hline $\mathrm{ZSC}(\mathrm{S})$ & 17 & 1639 & 485 & 118 \\
\hline Difference & 17 & 593.1 & 118.2 & 28.7 \\
\hline \multicolumn{5}{|c|}{ 95\% lower bound for mean difference: 543.1} \\
\hline \multicolumn{5}{|c|}{$\mathrm{T}$-Test of mean difference $=0(\mathrm{vs}>0): \mathrm{T}$-Value $=20.69 \mathrm{P}$-Value $=0.000$} \\
\hline \multicolumn{5}{|c|}{ Paired T-Test and Cl: ZSC(N); ZSC(S) } \\
\hline \multicolumn{5}{|c|}{ Paired T for ZSC(N) - ZSC(S) } \\
\hline & $\mathrm{N}$ & Mean & StDev & SE Mean \\
\hline $\mathrm{ZSC}(\mathrm{N})$ & 17 & 1681 & 487 & 118 \\
\hline $\mathrm{ZSC}(\mathrm{S})$ & 17 & 1639 & 485 & 118 \\
\hline Difference & 17 & 41.46 & 15.40 & 3.74 \\
\hline \multicolumn{5}{|c|}{ 95\% lower bound for mean difference: 34.94} \\
\hline \multicolumn{5}{|c|}{$\mathrm{T}$-Test of mean difference $=0(\mathrm{vs}>0): \mathrm{T}$-Value $=11.10 \mathrm{P}-$ Value $=0.000$} \\
\hline
\end{tabular}

The main effects of each leadership game in terms of five critical elements were calculated using MINITAB 16.5 software. The results are provided in figures of Table 10. In all models, Gama and $U$ have the least effect and $K$, Alpha and Beta have the greatest, which indicates that the sensitivity effect of a price and marketing changes on $\mathrm{SC}$ profit is greater than unit production costs. $\mathrm{K}$ has a direct effect on all three leadership models while Alpha has an inverse effect on the retailer leadership, and Beta has an inverse effect on the manufacturer and supplier models. Thus, it can be concluded that the increase in the selling prices would bring down the total profit; in addition, while the manufacturer and supplier act as leaders, increase in marketing cost would decrease the total profit as they would be making the first impact, which would require the retailer to invest more in marketing in order to gain a greater market share, based on demand equation. 

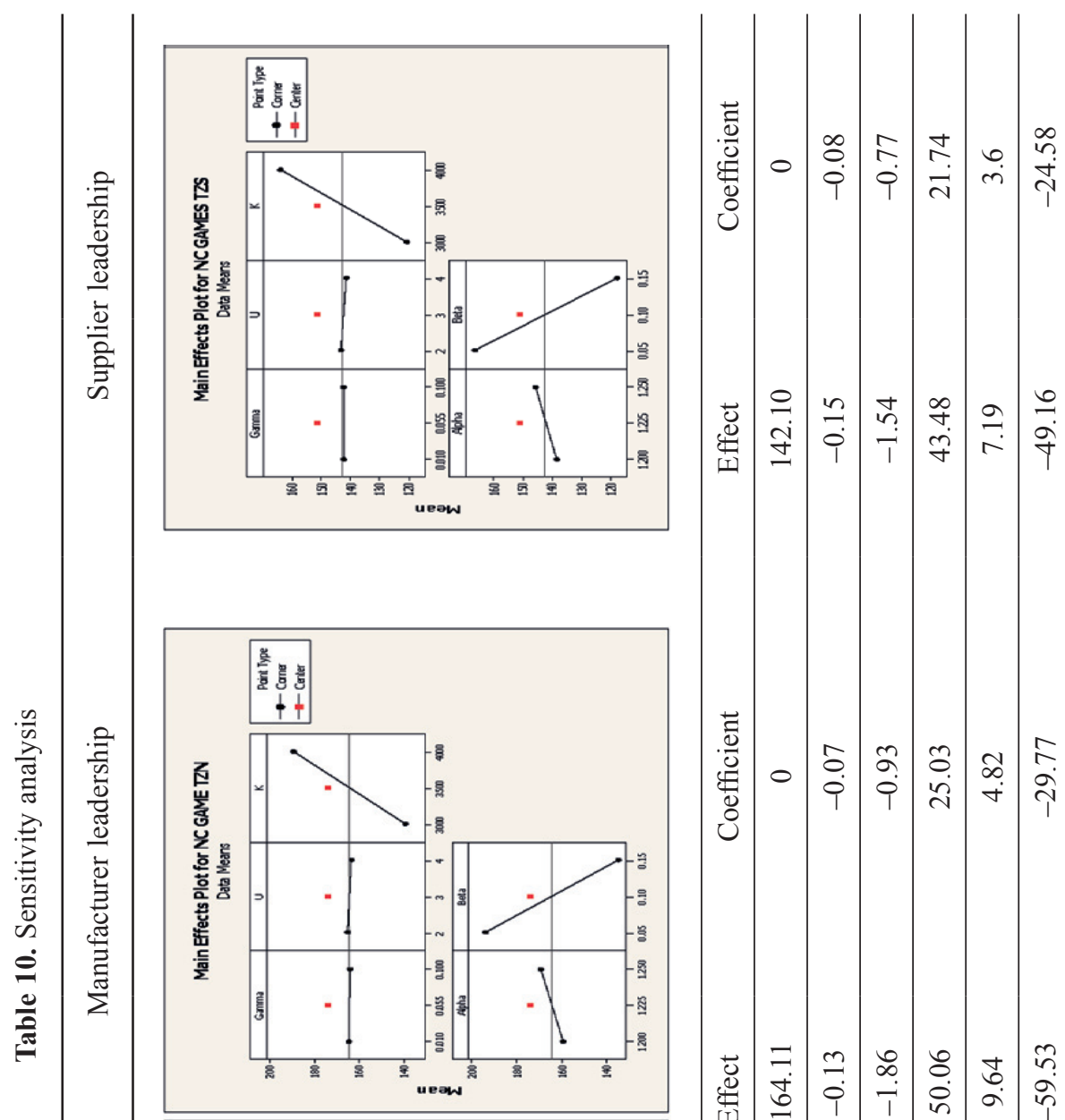

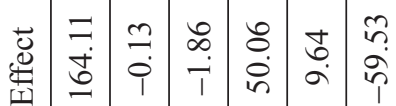

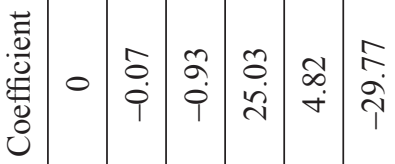

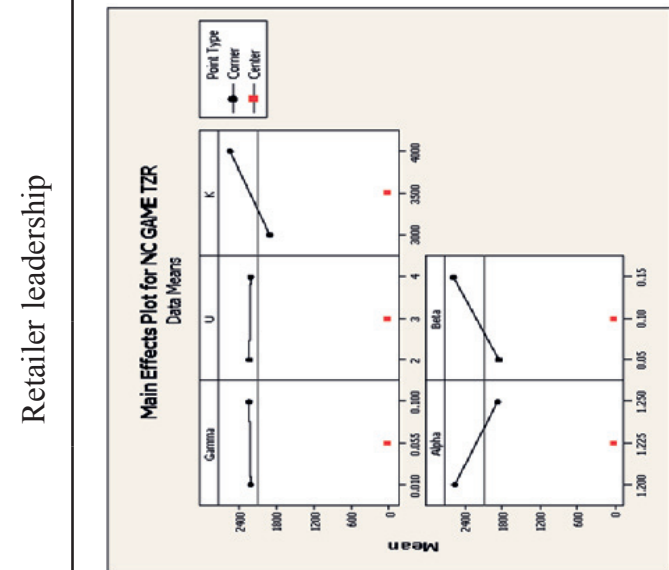

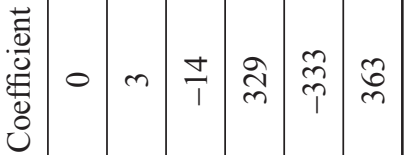

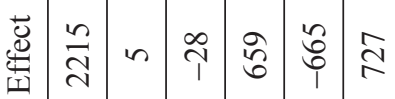

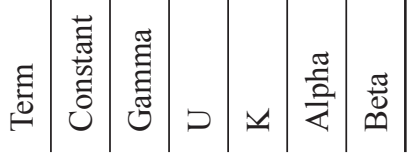




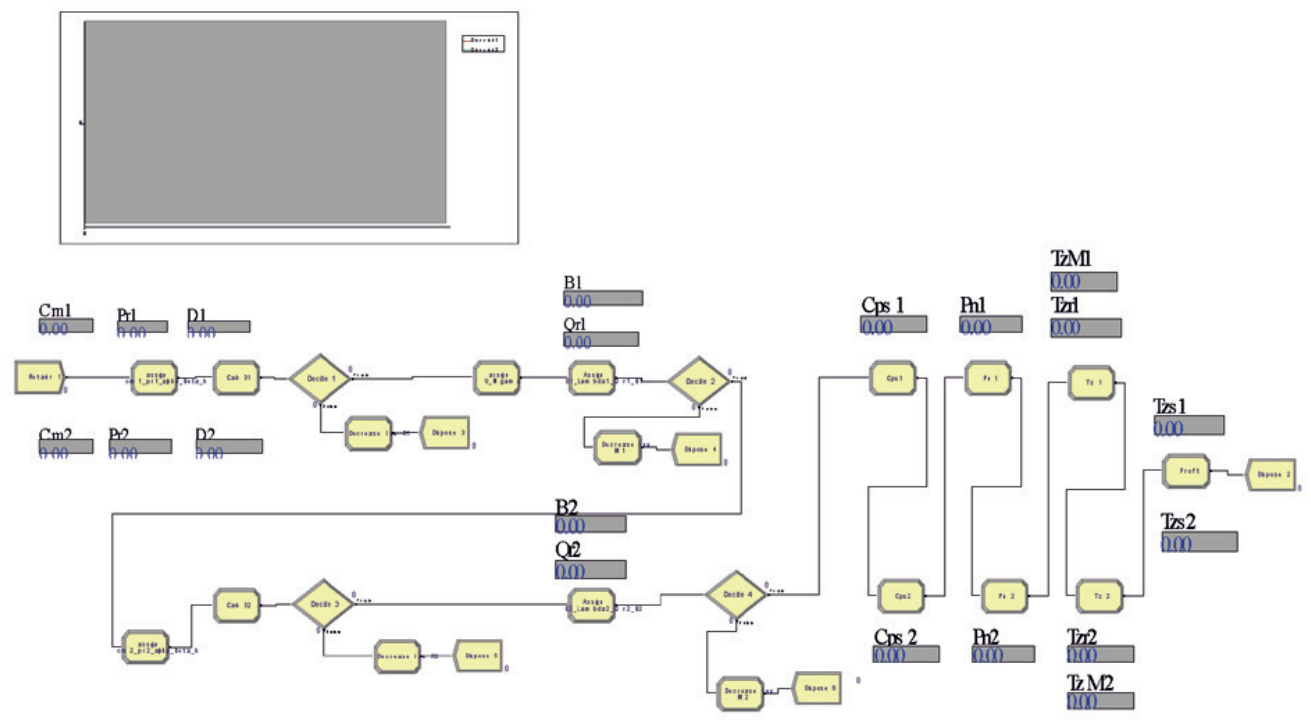

Fig. 3. Arena-based retailer leadership, a simulated model

Verification of different types of proposed leadership models based on non-cooperative game theory was delivered considering assumptions of models. For this purpose, a simulated supply chain was designed by Arena software, based on data from the aforementioned numerical example. The simulated model is demonstrated in Fig. 3. The simulated model is based on random marketing costs and a random retailer price, each retailer has a supply chain. By this randomisation, the demand of each product is computable and other decision variables are reached using the best response of each player calculated in the previous section, depending on Nash equilibrium definition.

The simulated model performed 100 runs for each type of experiment and the results are given in Table 11. As results suggest, the total profit of the supply chain in case of the proposed leadership model is similar to the total profit of SC based on Arena, where retailer is the leader. The SC total profit is always between the upper and lower bounds of the confidence interval.

Table 11. Model verification results in 17 experiments

\begin{tabular}{lccccc}
\hline Experiment & $\begin{array}{c}\text { Retailer leadership } \\
\text { model }\end{array}$ & $\begin{array}{c}\text { Ave total profit of } \\
\text { simulation }\end{array}$ & $\begin{array}{c}\text { Half } \\
\text { width }\end{array}$ & $\begin{array}{c}90 \% \text { Confidence } \\
\text { interval Min }\end{array}$ & $\begin{array}{c}\text { 90\% Confidence } \\
\text { interval Max }\end{array}$ \\
\hline Design 1 & $3,432.21$ & $3,302.76$ & 153.22 & $3,149.54$ & $3,455.98$ \\
\hline Design 2 & $1,838.18$ & $1,832.81$ & 85.30 & $1,747.51$ & $1,918.11$ \\
\hline Design 3 & $1,800.10$ & $1,810.25$ & 83.98 & $1,726.27$ & $1,894.23$ \\
\hline Design 4 & $1,370.40$ & $1,400.66$ & 64.99 & $1,335.67$ & $1,465.65$ \\
\hline Design 5 & $2,506.56$ & $2,457.33$ & 114.00 & $2,343.33$ & $2,571.33$ \\
\hline Design 6 & $2,554.22$ & $2,640.80$ & 114.16 & $2,526.64$ & $2,754.96$ \\
\hline
\end{tabular}


Continued Table 11

\begin{tabular}{lccccc}
\hline Experiment & $\begin{array}{c}\text { Retailer leadership } \\
\text { model }\end{array}$ & $\begin{array}{c}\text { Ave total profit of } \\
\text { simulation }\end{array}$ & $\begin{array}{c}\text { Half } \\
\text { width }\end{array}$ & $\begin{array}{c}90 \% \text { Confidence } \\
\text { interval Min }\end{array}$ & $\begin{array}{c}90 \% \text { Confidence } \\
\text { interval Max }\end{array}$ \\
\hline Design 7 & $2,129.12$ & $2,100.36$ & 97.44 & $2,002.92$ & $2,197.80$ \\
\hline Design 8 & $1,851.76$ & $1,820.40$ & 84.45 & $1,735.95$ & $1,904.85$ \\
\hline Design 9 & $1,878.19$ & $1,827.09$ & 84.76 & $1,742.33$ & $1,911.85$ \\
\hline Design 10 & $2,568.25$ & $2,461.21$ & 114.18 & $2,347.03$ & $2,575.39$ \\
\hline Design 11 & $1,394.95$ & $1,400.12$ & 64.95 & $1,335.17$ & $1,465.07$ \\
\hline Design 12 & $2,442.21$ & $2,431.24$ & 112.79 & $2,318.45$ & $2,544.03$ \\
\hline Design 13 & $2,469.80$ & $2,429.41$ & 112.71 & $2,316.70$ & $2,542.12$ \\
\hline Design 14 & $3,455.26$ & $3,307.45$ & 153.44 & $3,154.01$ & $3,460.89$ \\
\hline Design 15 & $2,528.73$ & $2,459.10$ & 114.10 & $2,345.00$ & $2,573.20$ \\
\hline Design 16 & $1,844.17$ & $1,879.58$ & 87.21 & $1,792.37$ & $1,966.79$ \\
\hline Design 17 & $1,890.24$ & $1,882.27$ & 50.00 & $1,832.27$ & $1,932.27$ \\
\hline
\end{tabular}

\section{Conclusion}

The research considered coordination in multi-echelon supply chains, in which non-cooperative game theory was used as a suitable tool for coordination of pricing, inventory and marketing expenditure policies in a three-level supply chain where the leadership changed depending on negotiating power. The situation and assumptions used in this paper will be valuable for future researches. In case of more levels, researchers are guided towards a comprehensive model, which would need to be coordinated in the future. In addition, as the competency of information and also complete information sharing in different levels seems to be impossible, using incomplete or imperfect game theory approaches such as signalling game or Nash Bayesian game would solve this problem and allow for more realistic options in the future. As interaction between layers in SC occurs continuously, repetitive games would adapt and fit real situations. This type of games considers time and patience of players within a modelling process.

The coordination mechanism used in this paper is based on leader follower Stackelberg game. It must be noted that other kinds and coordination options such as a profit sharing contract, revenue sharing contract, buyback contract and also option contract are all possible solutions for establishing coordination, Thus, the total profit and each stage profit would increase and bring more competitive advantages for the entire chain. The aforementioned contracts are all based on probabilistic demand function. Finally, Opt Quest application in Arena software is a suitable tool for estimating the best amounts of nonlinear model parameters. By identifying the optimal amount of the proposed models, optimal solution for unlimited three-echelon supply chain would be developed.

\section{References}

Abad, P. 1994. Supplier pricing and lot sizing when demand is price sensitive, European Journal of Operation Research 78(3): 334-354. http://dx.doi.org/10.1016/0377-2217(94)90044-2 
Arda, Y.; Hennet, J. C. 2005. Supply chain coordination through contract negotiation, in 44th IEEE Conference on Conference on Decision and Control, 12-15 December, 2005, Seville, Spain. IEEE, 4658-4684. http://dx.doi.org/10.1109/CDC.2005.1582897

Bahinipati, B. K.; Kanda, A.; Deshmukh, S. G. 2009. Revenue sharing in semiconductor industry supply chain: cooperative game theoretic approach, Sadhana 34(3): 501-527.

http://dx.doi.org/10.1007/s12046-009-0018-9

Bai, S.; Wang, D. 2008. Research on inventory game of supply chain based on credit coordination mechanism, in IEEE International Conference on Service Operations and Logistics, and Informatics, vol.2, 12-15 October, 2008, Beijing, China. IEEE, 3037-3042.

Bazaraa, M. S.; Sherali, H. D.; Shetty, C. M. 1993. Nonlinear Programming: Theory and Algorithms. John Wiley \& Sons.

Blanchard, D. 2010. Supply Chain Management Best Practices. John Wiley \& Sons.

Cachon, G. P.; Kok, G. A. 2010. Competing manufacturers in a retail supply chain: on contractual form and coordination, Management Science 56(3): 571-589.

http://dx.doi.org/10.1287/mnsc.1090.1122

Cachon, G. P.; Lariviere, M. A. 1999. Capacity allocation using past sales: when to turn and earn, Management Science 45(5): 685-703. http://dx.doi.org/10.1287/mnsc.45.5.685

Cachon, G. P.; Lariviere, M. A. 2001. Contracting to assure supply: how to share demand forecasts in a supply chain, Management Science 47(5): 629-646.

http://dx.doi.org/10.1287/mnsc.47.5.629.10486

Cachon, G. P.; Lariviere, M. A. 2005. Supply chain coordination with revenue sharing contracts: strength and limitations, Management Science 51(1): 30-44.

http://dx.doi.org/10.1287/mnsc.1040.0215

Cao, X.; Lu, R.; Yao, Z. 2007. A study on coordination in three stage perishable products supply chain based on false failure return, in IEEE International Conference on Grey Systems and Intelligent Services, 18-20 November 2007, Nanjing, China. IEEE, 1222-1227.

http://dx.doi.org/10.1109/GSIS.2007.4443467

Chakrabortty, S.; Pal, M.; Nayak, P. K. 2010. Solution of Interval-valued manufacturing inventory models with shortage, International Journal of Engineering and Applied Sciences 4(2): 89-94.

Chang, H. C. 2008. A note on the EPQ model with shortages and variable lead time, Information and Management Sciences 15(1): 61-67.

Chen, H.; Zhang, K. 2008. Stackelberg Game in a two echolon supply chain under buy back coordination contract, in IEEE International Conference on Service Operations and Logistics, and Informatics, vol. 2, 12-15 October, 2008, Beijing, China. IEEE, 201-208.

Chen, K.; Xiao, T. 2009. Demand disruption and coordination of the supply chain with a dominant retailer, Elsevier: European Journal of Operational Research 197(1): 225-234.

http://dx.doi.org/10.1016/j.ejor.2008.06.006

Chopra, S.; Meindel, P. 2007. Supply Chain Management, 3rd edition. New York: Prenticehall.

Esmaeili, M.; Aryanejad, M.; Zeephongsekul, P. 2008. A game theory approach in seller-buyer supply chain, European Journal of Operation Research 195(2): 442-448.

http://dx.doi.org/10.1016/j.ejor.2008.02.026

Feng, J. S.; Jia, L. M.; Jiao, H. L. 2007. The three stage supply chain coordination by revenue sharing contracts, in IEEE International Conference on Grey Systems and Intelligent Services, 18-20 November, 2007, Nanjing, China. IEEE, 1216-1221.

http://dx.doi.org/10.1109/GSIS.2007.4443466

Feng, S. X. 2008 Coordination of pricing decisions in multiple product supply chains, in Wireless Communications, Networking and Mobile Computing, 2008. WiCOM '08, 12-14 October, 2008, Dalian, China. IEEE, 16-22. 
Gumus, T. A.; Guneri, F. A. 2007. Multi-echelon inventory management in supply chains with uncertain demand and lead times: literature review from an operational research perspective, Journal of Engineering Manufacture 221(10): 1553-1570. http://dx.doi.org/10.1243/09544054JEM889

Gupta, D.; Weerawat, W. 2006. Supplier manufacturer coordination in capacitated two stage supply chains, Elsevier: European Journal of Operational Research 175(1): 67-89.

http://dx.doi.org/10.1016/j.ejor.2005.04.021

Hennet, J. C.; Arda, Y. 2008. Supply chain coordination; a game theory approach, Engineering Applications of Artificial Intelligence 21(3): 399-405.

http://dx.doi.org/10.1016/j.engappai.2007.10.003

Jaafarnejad, A.; Amoozad Mahdiraji, H.; Mohaghar, A.; Modarresyazdi, M. 2012. retailers leadership mathematical modeling in unlimited three echelon supply chain: non-cooperative game theory approach, Archives Des Science 65(6): 81-90.

Jaber, M. Y.; Osman, I. H.; Guiffrida, A. L. 2006. Coordinating a three level supply chain with price discounts, price dependent demand, and profit sharing, International Journal of Integrated Supply Chain 2(1/2):28-49. http://dx.doi.org/10.1504/IJISM.2006.008337

Jespersen, B. D.; Larsen, S. T. 2005. Supply chain management: in theory and practice. Copenhagen: Copenhagen Business School Press.

Jiazhen, H.; Qin, L. 2008. Revenue coordination contract based on stackelberg game in upsteam supply chain, in Wireless Communications, Networking and Mobile Computing, 2008. WiCOM '08, 12-14 October, 2008, Dalian, China. IEEE, 1-5. http://dx.doi.org/10.1109/WiCom.2008.1

Jung, H.; Cerry, M. K. 2005. Optimal inventory policies for an economic order quantity model with decreasing cost functions. European Journal of Operation Research 165(1): 108-126.

http://dx.doi.org/10.1016/j.ejor.2002.01.001

Jung, H.; Cerry, M. K. 2001. Optimal inventory policies under decreasing cost functions via geomettric programming. European Journal of Operation Research 132(3): 628-642.

http://dx.doi.org/10.1016/S0377-2217(00)00168-5

Kaviani, M. R.; Chaharsooghi, K.; Naimi Saidgh, A. 2011. Stackelberg game theory approach for manufacturer-retailer supply chain coordination using Imperialist Competitive Algorithm, in Logistics and Supply Chain Conference, 22-23 November, 2011, Tehran, Iran. 130-145.

Kim, D.; Lee, J. W. 1998. Optimal joint pricing and lotsizing with fixed and virable capacity, European Journal of Operation Research 109(1): 212-227.

http://dx.doi.org/10.1016/S0377-2217(97)00100-8

Lee, J. W. 1993. Determining order quantity and selling price by geomettric programming, Decesion Science 21(1): 76-87. http://dx.doi.org/10.1111/j.1540-5915.1993.tb00463.x

Lee, J. W.; Kim, D.; Cabot, A. V. 1996. Optimal demand rate, lotsizind and process reliability improvement decisions, IEEE Trasactions: 941-952.

Leng, M. M.; Parlar, M. 2009. Allocation of cost savings in a three level supply chain with demand information sharing: a cooperative game approach, Operations Research 57(1) 200-213. http://dx.doi.org/10.1287/opre.1080.0528

Leng, M. M.; Parlar, M. 2010. Game theoretic analysis of decentralized assembly supply chains: non cooperative equilibria vs. coordination with cost sharing contracts, Elsevier: European Journal of Operational Research 204(1): 96-104. http://dx.doi.org/10.1016/j.ejor.2009.10.011

Leng, M. M.; Zhu, A. 2009. Side payments contracts in two person nonzero sum supply chain games: review, discussion and applications, Elsevier: European Journal of Operational Research 196(2): 600-618. http://dx.doi.org/10.1016/j.ejor.2008.03.029

Liu, Y.; Zhang, H. 2006. Supply chain coordination with contracts for online game industry, in 3rd IEEE International Conference on Management of Innovation and Technology, vol. 2, 21-23 June, 2006, Singapore, IEEE 867-872. http://dx.doi.org/10.1109/ICMIT.2006.262345 
Mentzer, J. T. 2001. Supply chain management, 2nd edition. California: Sage Publication.

Mentzer, J. T.; Dewitt, W.; Keebler, J. S.; Min, S.; Nix, N. W.; Smith, C. D., et al. 2001. Difining supply chain management b, Journal of Business Logistics 22(2): 1-25.

http://dx.doi.org/10.1002/j.2158-1592.2001.tb00001.x

Nash, J. 1950a. Equilibrium points in n-person games, Proceeding of National Academy of Science 36(1): 48-49. http://dx.doi.org/10.1073/pnas.36.1.48

Nash, J. 1950b. Bargaining problem, Econometrica 18(2): 155-162.

http://dx.doi.org/10.2307/1907266

Nash, J. 1951. Non cooperative games, Annal of Mathematics 54(2): 286-295.

http://dx.doi.org/10.2307/1969529

Oganezov, K. N. 2006. Inventory Models Fpr Production Systems with Constant Linear Demand, Time Value of Money and Perishable or Nonperiashable Items. Virginia: West Virginia University.

Pentico, D. W.; Drake, M. J.; Toews, C. 2009. The deterministic EPQ with partial backordering: a new approach, Omega: The International Journal of Management Science 37(3): 624-636. http://dx.doi.org/doi:10.1016/j.omega.2008.03.002

Rasmusen, E.; Blackwell, B. 2005. Games and Information; an Introduction to Game Theory, fourth ed. Indiana: Indiana University Press.

Stank, T. P.; Davis, B. R.; Fugate, B. S. 2005. A strategic framework for supply chain oriented logistics, Journal of Business Logistics 26(2): 27-46.

http://dx.doi.org/10.1002/j.2158-1592.2005.tb00204.x

Stein, H. D. 2010. Allocation rules with outside option in cooperation games with time inconsistency. Journal of Business Economics and Management 11(1): 56-96.

http://dx.doi.org/10.3846/jbem.2010.04

Stein, H. D.; Ginevicius, R. 2010a. Overview and comparison of profit sharing in different business collabration forms. Journal of Business Economics and Management 11(3): 428-443. http:// dx.doi.org/10.3846/jbem.2010.2121

Stein, H. D.; Ginevicius, R. 2010b. New coopettion approach for supply chain applications and the implementation a new allocation rule, in 6th International Scientific Conference, May 13-14, 2010, Vilnius, Lithuania. Vilnius: Technika, 147-152.

Wang, L.; Sun, X.; Dang, F. 2009. Dynamic cooperation mechanism in supply chain for perishable agricultural products under one to multi. Springer, 1212-1221.

Wang, W. Y.; Michael, H. S.; Patrick, Y. 2007. Supply chain management: issues in the new era of collaboration and competition. Pensylvania: Idea Group Publishing.

Wang, X.; Tang, W. .2009. Fuzzy EPQ inventory models with backorder, Journal of System and Science Complexity 22(2): 313-323. http://dx.doi.org/10.1007/s11424-009-9166-6

Xiao, T.; Qi, X. 2008. Price competition, cost and demand disruptions and coordination of a supply chain with one manufacturer and two competing retailers, Omega: The International Journal of Management Science 36(5): 741-753. http://dx.doi.org/10.1016/j.omega.2006.02.008 Xiao, T.; Qi, X.; Yu, G. 2007. Coordination of supply chain after demand disruptions when retailers compete, Elsevier: International Journal of Production Economics 109(1-2): 162-179. http://dx.doi.org/10.1007/s11424-009-9166-6

$\mathrm{Xu}, \mathrm{Y}$; Zhong, H. 2011. Benefit mechanism designing: for coordinating three stages supply chain, in International Conference on Management Science and Industrial Engineering (MSIE), 8-11 January, 2011, Harbin, China. IEEE, 966-971.

Yali, L.; Zhanguo, L. 2010. Coordination of price discount and sales promotion in a two level supply chain system, in IEEE International Conference on Emergency Management and Management Sciences (ICEMMS), 8-10 August, 2010, Beijing, China. IEEE, 421-427. 
Ying, H. L.; Qi, C. Y.; Sheng, J. Z. 2007. Research on the coordination mechanism model of the three level supply chain, in International Conference on Management Science and Engineering (ICMSE 2007), 20-22 August, 2007, Harbin, China. IEEE, 20-25.

Zhang, X.; Huang, G. Q. 2010. Game theoretic approach to simultaneous configuration of platform products and supply chains with one manufacturing firm and multiple cooperative suppliers, International Journal of Production Economics 124(1): 121-136.

http://dx.doi.org/10.1016/j.ijpe.2009.10.016

Zhao, Y.; Wang, S.; Cheng, T. E.; Yang, X.; Huang, Z. 2010. Coordination of supply chains by option contracts: a cooperative game theory approach, European Journal of Operational Research 207(2): 668-675. http://dx.doi.org/10.1016/j.ejor.2010.05.017

Zhen, L.: Xiaoyuan, H.: Shizheng, G. 2006. The study on stackelberg game of supply chain coordination with uncertain delivery, in International Conference on Service Systems and Service Management, 25-27 Octtober, 2006, Troyes, France. IEEE, 1460-1465.

http://dx.doi.org/10.1109/ICSSSM.2006.320739

Peng JIA has received the Doctor's Degree in Engineering at Nagoya University, Japan. He is an Assistant Professor of Transportation Management College and the Vice-Director of Institute of Corporation of Social Responsibility and Sustainable Development (ICSD) at Dalian Maritime University, where he teaches courses on Transport Geography and Spatial Systems. His research is focused on supply chain management, corporate social responsibility, transport network optimisation and spatial simulation.

Hannan AMOOZAD MAHDIRAJI received his Ph.D. and masters degrees in operation and manufacturing management from the University of Tehran and bachelors in industrial engineering. He is an Assistant Professor of Kashan branch, Islamic Azad University, and also Chief of Planning and Systems Department of Iran Mercantile Exchange. He has published nearly 15 papers related to supply chains and MCDM models in international journals and conferences.

Kannan GOVINDAN is currently an Associate Professor of operations and supply chain management at the Department of Business and Economics, University of Southern Denmark, Odense M, Denmark. His research interests include logistics, supply chain management, green and sustainable supply chain management, reverse logistics and maritime logistics. He has published more than 65 papers in refereed international journals and more than 70 papers in conferences. He was awarded a gold medal for the Best Ph.D. Thesis.

Ieva MEIDUTE். Assoc. Prof., Dr of technological sciences (transport engineering), Vilnius Gediminas Technical University, Faculty of Business Management, Department of Business Technologies. Her research interests are related with business process management, logistics and supply chain management. 